\title{
Numerical simulations of long term global mantle convection with crust production: advanced features and recent results
}

\author{
ANTOINE BILLY ROZEL ${ }^{1}$, DIOGO LOURO LOURENCO ${ }^{2}$, \\ CHARITRA JAIN ${ }^{3}$, PAUL J. TACKLEY ${ }^{1}$ AND TARAS \\ GERYA $^{4}$ \\ ${ }^{1}$ ETH Zürich \\ ${ }^{2}$ Berkeley University \\ ${ }^{3}$ GFZ German Research Centre for Geosciences, Geodynamic \\ Modelling Section \\ ${ }^{4}$ ETH Zurich \\ Presenting Author: antoinerozel@gmail.com
}

The presentation will highlight advanced global numerical simulations of mantle convection and is designed for a broader audience without prior knowledge of modeling techniques. Specific features such as melting, crust production and core cooling in the code "StagYY" will be introduced.

Over the last years, it has been shown that melting and crust production might be the processes dominating the evolution of warm planetary mantles such as the early Earth, Venus or Io. Regarding the Earth, several possible pre-plate tectonics convection regimes have been observed and will be presented. Recent simulations in which continental crust is self-consistently formed will be detailed.

Since those simulations certainly do not reproduce the geochemical complexity of the Earth, what can still be learnt? How is crustal material formed? I will present both strengths and weaknesses of our models. 